\title{
ASSESSMENT OF PERIODIC DISSIMILARITY OF PHYTOCHEMICAL AND ANTIDIARRHEAL ACTIVITY OF ETHANOLIC EXTRACT OF PSIDIUM GUAJAVA LINN (MYRTACEAE) LEAVES USING WISTAR ALBINO RATS
}

\author{
UTTAM BORAH*, BISWAJIT DASH, JASHABIR CHAKRABORTY \\ Department of Pharmacology, Girijananda Chowdhury Institute of Pharmaceutical Science, Azara, Guwahati, \\ Assam, India. Email: borahuttam2017@gmail.com
}

Received: 10 September 2017, Revised and Accepted: 11 October 2017

ABSTRACT

Objective: The current investigation was achieved to treasure out the modification of antidiarrheal activity of ethanoic leaves extract of Psidium guajava Linn. with respect to change of season, namely, autumn and spring.

Methods: The castor oil induced diarrhea method is employed for assessment of periodic dissimilarity of antidiarrheal activity of ethanolic extract of P. guajava Linn. (Myrtaceae) leaves. Phytochemical variation is resolute as per typical procedure using various reagents.

Results: Phytochemical scrutiny discloses that small fluctuation of phytoconstituent content was observed. The extract was initially assayed for its possessions in castor oil-induced diarrhea at different doses $(200,400$, and $600 \mathrm{mg} / \mathrm{kg}$, p.o.). There was statistically noteworthy lessening $(\mathrm{p}<0.05)$ in the number of wet feces by $78.33 \%$ during spring season and $78.26 \%$ during autumn season at $600 \mathrm{mg} / \mathrm{kg}$ body weight, and when compared to negative control rats, which might be due to change in climate or due to alteration in plant biosynthesis pathway in different season.

Conclusion: The outcomes deliver the suggestion for variation in phytochemical contents as well as amendment in antidiarrheal activity of ethanoic extract of P. guajava leaves during autumn and spring.

Keywords: Psidium guajava, Diarrhea, Castor oil, Seasonal variation, Phytochemicals, Autumn, Spring.

(C) 2018 The Authors. Published by Innovare Academic Sciences Pvt Ltd. This is an open access article under the CC BY license (http://creativecommons. org/licenses/by/4. 0/) DOI: http://dx.doi.org/10.22159/ajpcr.2018.v11i1.22842

\section{INTRODUCTION}

The diarrhea is a noteworthy topic in Third World nations and is in custody of the demise of a great many individuals consistently. Diarrhea is a alteration in ordinary solid discharge and is represented by an increase in the water substance, volume, or recurrence of stools [1].

Meanwhile, plants have carried a different scope of bioactive atoms, making them the upscale supply of numerous sorts of keys. Around $20 \%$ of the plants originate on the Earth have been give into the pharmaceutical, and a reasonable number of new hostile to disease specialists introduced in the market are gotten from general or semi-fabricated resources [2].

Psidium guajava or else called Madhuriam (Assamese) is an authoritative nutrition trim, and restorative plant in tropical and subtropical nations is roughly utilized like nourishment and in people pharmaceutical everywhere of the world. In addition, had been recognized the liberatingly critical phytoconstituents. Various metabolites in great yield and some have been appeared to have helpful organic exercises having a place mainly with phenolic, flavonoid, carotenoid, terpenoid, and triterpene. Concentrates and metabolites of this plant, especially those from leaves and natural products, have appreciated pharmacological exercises. An impression of the writing validates $P$. guajava is utilized broadly

as the hypoglycemic specialist [3]. Numerous pharmacological inspections have shown the capacity of this plant to display cancer prevention agent, hepatic protection, against hypersensitivity, antimicrobial, antigenotoxic, antiplasmodial, cytotoxic, antispasmodic, cardioactive, anticough, antidiabetic [4], anti-inflammatory, and antinociceptive exercises, supporting

conventional employments. Recommend an extensive variety of clinical applications for the treatment of antidiarrheal [5].
Therefore, this enquiry proposed to determine the sessional diversity of antidiarrheal movement of the ethanol extract from the leaves of P. guajava, on castor oil-induced diarrhea $(200,400$, and $600 \mathrm{mg} / \mathrm{kg}$ ) model. It also looks after the phytochemical variation.

\section{METHODS}

Plant materials collection

The fledgling leaves of the plant were composed from Lakhimpur district of Assam during two seasons. The plant was recognized and authenticated by the Department of Botany, Guwahati University (Reference No.Herb/Bot./Gu/2017/26). Then, it was eroded and then dehydrated in tray dryer and was shaped into powder mechanically.

Chemicals and reagents

Petroleum ether (PE), ethanol (ET), dimethyl sulfoxide, hydrochloric acid, Dragondorff reagent, Mayer's reagent, Wagner's reagent, Benedict's reagent, sulfuric acid, lead acetate, Molisch's reagent, Fehling solution A and B, sodium citrate, copper sulfate, ferric chloride, sodium hydroxide, glacial acetic acid, benzene, chloroform, ammonia, nitric acid, potassium nitrite, gelatin, castor oil, loperamide, and normal saline were used. All the chemicals and solvents used were of standard analytical grades.

\section{Preparation of the leaves extract}

The desiccated and powdered plant substantial was defatted using PE and then extracted with ET in the order of their growing polarity by maceration process until it got to be distinctly dreary as specified by the standard techniques [6]. The ethanolic extract was strenuous using rotary vacuum evaporator and pack up in the refrigerator for further enquiry. 
The extract developed was balanced, and the rate yield was guessed as far as the dried weight of the plant material utilizing the following calculation:

$\%$ Yield $=($ Dry weight of the extract/Dry weight of leaf sample $) \times 100$

The covering and reliability of the concentrate were moreover noted.

\section{Physicochemical screening [7]}

The physicochemical constraints were resolute as per the WHO guidelines.

\section{Loss on drying}

About 2-5 g of the powered drugs material into a weighted flat and thin porcelain dish then dried in the oven at $100^{\circ} \mathrm{C}$ or $150^{\circ} \mathrm{C}$ until two consecutive weighing did not differ by more than $0.5 \mathrm{mg}$. Cooled in a desiccator and token the weight of drug material. The loss in weight was usually regarded as moisture.

The loss of weight (in gram) of air-dried was calculated as follows:

$$
\text { Moisture content }(\%)=\frac{\text { Weight loss } \times 100}{\text { Weight of the sample }}
$$

\section{Total ash}

Around 2-4 g of the air-dried material was precisely weighed, in a formerly touched off and tared pot (for the most part of platinum or silica). Spread the material in an even layer and touch off it by step-bystep expanding the warmth to $500-600^{\circ} \mathrm{C}$ until the point that it was white in shading that showing the nonattendance of carbon. Cooled in a desiccator and taken weigh.

\section{Corrosive insoluble ash}

The pot containing the aggregate fiery debris included $25 \mathrm{ml}$ of hydrochloric corrosive and secured with a watch glass and bubbled delicately for $5 \mathrm{~min}$. The watch glass was washed with $5 \mathrm{ml}$ of high temperature water and added this fluid to the cauldron. The insoluble issue was gathered on a powderless channel paper and washed with heated water until the point that the filtrate was unbiased. The channel paper was exchanged to the first cauldron containing the insoluble issue and dried on a hot-plate and touched off to steady weight. The deposit was permitted to cool in an appropriate desiccator for $30 \mathrm{~min}$, at that point weigh immediately. Compute the substance of corrosive insoluble cinder in mg per $\mathrm{g}$ of air-dried material.

\section{Water soluble ash}

The pot containing the aggregate fiery remains included $25 \mathrm{ml}$ of water and bubbled for $5 \mathrm{~min}$. The insoluble issue was gathered in a sinteredglass cauldron or on a cinder less channel paper, washed with heated water, and lighted in a pot for $15 \mathrm{~min}$ at a temperature not surpassing $450^{\circ} \mathrm{C}$. Subtract the heaviness of this deposit in $\mathrm{mg}$ from the heaviness of aggregate fiery remains. Figure the substance of water-solvent slag in mg per g of air-dried material [8]

\section{Phytochemical screening [9]}

The plant separate was examined for the proximity of alkaloids, saponin, flavonoids, phenol, sugars, proteins and amino acids, heart glycosides, steroids, anthraquinone, and terpenoids utilizing the standard methodologies.

\section{Location of alkaloids}

Extract was broken up in weaken hydrochloric corrosive and sifted.

a. Mayer's test: Filtrates were treated with Mayer's reagent (potassium mercuric iodide). Arrangement of a yellow-shaded hasten shows the nearness of alkaloids.

b. Wagner's test: Filtrates were treated with Wagner's reagent (iodine in potassium iodide). Development of darker/ruddy encourage demonstrates the nearness of alkaloids.

c. Dragendroff's test: Filtrates were treated with Dragendroff's reagent (arrangement of potassium Bismuth Iodide). Development of red hasten demonstrates the nearness of alkaloids.

\section{Identification of saponins}

Froth test: $0.5 \mathrm{~g}$ of concentrate was shaken with $2 \mathrm{ml}$ of water. In the event that froth delivered continues for $10 \mathrm{~min}$, it demonstrates the nearness of saponins.

\section{Identification of flavonoids}

Lead acetic acid derivation test: Extract was treated with few drops of lead acetic acid derivation arrangement. Development of yellowshading hasten demonstrates the nearness of flavonoids.

\section{Recognition of starches}

The extract was broken down exclusively in $5 \mathrm{ml}$ refined water and separated. The filtrates were utilized to test for the nearness of starches.

a. Molisch's test: Filtrates were treated with 2 drops of alcoholic $\alpha$-naphthol arrangement in a test tube. Development of the violet ring at the intersection demonstrates the nearness of carbohydrates.

b. Benedict's test: Filtrates were treated with Benedict's reagent and warmed tenderly. Orange-red encourage shows the nearness of diminishing sugars.

c. Fehling's test: Filtrates were hydrolyzed with diluted $\mathrm{HCl}$, killed with salt, and warmed with Fehling's A and B arrangements. Development of red accelerate demonstrates the nearness of decreasing sugars.

\section{Discovery of glycosides}

The extract was hydrolyzed with diluted $\mathrm{HCl}$ and after that subjected to test for glycosides.

Changed Borntrager's test: Extract was treated with ferric chloride arrangement and drenched in bubbling water for around $5 \mathrm{~min}$. The blend was cooled and separated with the rise to volumes of benzene. The benzene layer was isolated and treated with smelling salts arrangement. Development of rose-pink shading in the ammonical layer shows the nearness of anthranol glycosides.

\section{Discovery of phytosterols}

Salkowski's test: Extract was treated with chloroform and sifted. The filtrates were treated with few drops of concentrated sulfuric corrosive, shaken and permitted to stand. The appearance of brilliant yellow shading shows the nearness of triterpene.

\section{Identification of proteins and amino acids}

Xanthoproteic test: The extract was treated with few drops of concentrated nitric corrosive. Development of yellow shading demonstrates the nearness of proteins.

\section{Identification of tannins}

Gelatine test: To the concentrate, $1 \%$ gelatine arrangement containing sodium chloride was included. Development of white encourage demonstrates the nearness of tannins.

\section{Quantitative phytochemical analysis}

Total phenols determination [10]

The measures of aggregate phenolic substance of concentrates were controlled by the spectrophotometric technique for Kim et al., with slight prescription. A weakened plant separate $(1 \mathrm{ml})$ or gallic corrosive standard phenolic compound was added to a $25 \mathrm{ml}$ volumetric carafe, containing $9 \mathrm{ml}$ of refined water. $1 \mathrm{ml}$ of Folin-Ciocalteu's phenol reagent was added to the blend and shaken. After $5 \mathrm{~min}, 10 \mathrm{ml}$ of $7 \%$ Na2C03. Total flavonoids determination arrangement was blended into 
the test. The arrangement was weakened to $25 \mathrm{ml}$ refined water and blended completely. The blend was kept oblivious for $90 \mathrm{~min}$ at $23^{\circ} \mathrm{C}$, after which the absorbance was perused at $750 \mathrm{~nm}$. Add up to phenol content was resolved from extrapolation of adjustment bend which was made by planning gallic corrosive arrangement. The estimation of the phenolic mixes was completed in triplicate. The total phenolic content was communicated as milligrams of gallic corrosive counterparts per gram of dried specimen (Table 1).

\section{Total tannin determination [11,12]}

Explanatory technique for quantitative assurance of tannin was by Amadi et al. what's more, Ejikeme et al. The accompanying recipe was utilized as a part of the estimation:

$$
\text { Tannic acid } \frac{(\mathrm{mg})}{(100 \mathrm{~g})}=\frac{\mathrm{C} \times \text { extract volume } \times 100}{\text { Aliquot volume } \times \text { Weight of sample }}
$$

\section{Total flavonoids determination [13]}

The aggregate flavonoids examine was led by Katasani. Add up to flavonoids content was controlled by utilizing aluminum chloride colorimetric technique. Each plant removes $(0.5 \mathrm{ml})$ were blended with $1.5 \mathrm{ml}$ of methanol, $0.1 \mathrm{ml}$ of $10 \%$ aluminum chloride, $0.1 \mathrm{ml}$ of $1 \mathrm{M}$ potassium acetic acid derivation, and $2.8 \mathrm{ml}$ of refined water. It stayed at room temperature for $30 \mathrm{~min}$. The absorbance of the response blend was measured at $510 \mathrm{~nm}$ utilizing ultraviolet -visible spectrophotometer. The adjustment bend was set up by planning quercetin arrangements at focuses $2-8 \mu \mathrm{g} / \mathrm{ml}$ in methanol. The total flavonoid content was communicated as milligrams of quercetin counterparts per gram of dried example (Table 1). The level of flavonoid was computed as follows:

$$
\% \text { Flavonoid }=\frac{\text { Weight of flavonoids }}{\text { Weight of Sample }} \times 100
$$

\section{Determination of saponin [14]}

Saponin quantitative assurance was completed by utilizing the strategy revealed by Ejikeme et al., and furthermore, by Obadoni and Ochuko.

The level of Saponin was ascertained as follows:

$$
\% \text { Saponin }=\frac{\text { Weight of Saponin }}{\text { Weight of Sample }} \times 100
$$

\section{Antidiarrheal activity}

\section{Animals}

Wistar pale skinned person rats of either sex measuring 120-200g were kept up at $25 \pm 2^{\circ} \mathrm{C}$ temperature, $50 \pm 15^{\circ} \mathrm{C}$ relative moistness, and ordinary photoperiod (12 h dull/12 h light) in plastic confines. The creatures were sustained standard pellet eating regimen and water not obligatory. All the creature tests were completed as per the rules of the CPCSEA and were affirmed by the Institutional Animal Ethical Committee.

\section{Antidiarrheal measure (castor oil instigated method)}

The antidiarrheal action of ethanoic remove was assessed by the technique portrayed by Teke et al., 2007. Rats were fasted for $18 \mathrm{~h}$ and isolated into five gatherings of five creatures each gathering. Castor oil at a dosage of $1 \mathrm{ml}$ was offered orally to all gatherings of creatures for the enlistment of loose bowels. $1 \mathrm{~h}$ preceding castor oil organization, different medicines were given, Group I (control) and given typical saline arrangement, Group II (standard) was treated with loperamide ( $3 \mathrm{mg} / \mathrm{kg}$ p.o.), a positive control. Gathering III-V were regulated ethanolic separate $P$. guajava $(200,400$, and $6000 \mathrm{mg} / \mathrm{kg}$ ) individually by oral course. Creatures were put independently in singular confines fixed with channel paper. The channel papers were changed each hour, and the seriousness of the runs was surveyed hourly for $4 \mathrm{~h}$ [15]

\section{RESULTS}

Physicochemical and phytochemical examination

The rate yields of the ethanolic separates were observed to be $11.37 \% \mathrm{w} / \mathrm{w}$ in autumn and $11.02 \% \mathrm{w} / \mathrm{w}$ in spring. The powdered leaves of P. guajava were subjected to assess its dampness content, add up to a cinder, corrosive insoluble fiery debris, water-dissolvable slag esteem. The air-dried specimen contains 14.67 and $14.64 \%$ dampness. The low dampness substance of the leaf would thwart the development of microorganism, and capacity life would be high. The aggregate fiery remains (8.72 and $8.70 \%$ ) show that the leaf is similarly rich in mineral components. Corrosive insoluble and water dissolvable fiery remains esteems were discovered 1.4 and $1.6 \%$ and 7.2 and $7.0 \%$ individually as summarized in Table 2

The results of the phytochemical screening showed that the ethanolic organic product concentrate of P. guajava contained alkaloids, saponin, flavonoid, starch, glycosides, steroid, proteins and amino acids, and tannin. The phytochemical investigation is delighted in Table 3.

The ethanolic leaf separate was subjected for add up to optional metabolites substance of the plant and discovered variety in their substance amid two unique seasons. Phytochemical screening of the concentrate demonstrated abnormal amounts of tannins and flavonoids which is summarized in Table 1 .

\section{Intense toxicity}

The most overwhelming indications of intense poisonous quality impacts were worked breathing, bothering, rear appendage loss of motion, shakings, and ataxia. The seriousness of the indications of

Table 1: Difference in secondary metabolites during two dissimilar seasons of the ethanoic extract of P. guajava

\begin{tabular}{lll}
\hline $\begin{array}{l}\text { Secondary } \\
\text { metabolite }\end{array}$ & During autumn (mg/g) & During spring (mg/g) \\
\hline Phenol & $9.32 \pm 0.63$ & $8.1 \pm 0.53$ \\
Tannin & $4.22 \pm 0.32$ & $4.54 \pm 0.32$ \\
Flavonoid & $6.54 \pm 0.43$ & $5.44 \pm 0.32$ \\
Saponin & $3.45 \pm 0.24$ & $4.15 \pm 0.27$ \\
\hline
\end{tabular}

Values are expressed in Mean \pm SD for triplicates, SD: Standard deviation

Table 2: Moisture content total ash value acid and water insoluble ash value in two dissimilar seasons autumn and spring

\begin{tabular}{ll}
\hline Proximate analysis & Amount (\%) \\
\hline Moisture content & $14.67 \%$ (spring), 14.64\% (autumn) \\
Total ash value & $8.72 \%$ (spring), 8.70\% (autumn) \\
Acid insoluble ash value & $1.4 \%$ (spring), 1.6\% (autumn) \\
Water insoluble ash value & $7.2 \%$ (spring), 7.0\% (autumn) \\
\hline
\end{tabular}

Table 3: Phytochemical analysis of the ethanoic extract of P. guajava

\begin{tabular}{lll}
\hline Phytochemical & $\begin{array}{l}\text { Intensity of secondary } \\
\text { metabolite }\end{array}$ & Autumn \\
\cline { 2 - 3 } & Spring & ++ \\
\hline Tannins & ++ & ++ \\
Alkaloids & ++ & ++ \\
Steroidal glycoside & +++ & ++ \\
Flavonoids & +++ & ++ \\
Saponins & ++ & \\
\hline
\end{tabular}

-+ +: Shows the intensity 
lethality expanded with increment in the dosage. There was no watched indication of lethality in the gathering of mice that got ordinary saline. The mice were regulated up to measurements of $2000 \mathrm{mg} / \mathrm{kg}$, and no indication of poisonous quality was seen according to O.E.C.D rules 423 .

\section{Hostile to diarrheal activity of $P$. guajava}

The mean recurrence of wet fecal droppings diminished with increment in dosage of the ethanolic leaf concentrate of $P$. guajava got amid two unique seasons, with the mean recurrence of poop being lower in the rats that was treated with $600 \mathrm{mg} / \mathrm{Kg}$ and higher in the gatherings that was treated with $400 \mathrm{mg} / \mathrm{Kg}$ and $200 \mathrm{mg} / \mathrm{Kg}$ individually as summarized in Table 4. The mean recurrence of wet fecal droppings for the rats in the loperamide-treated gathering was 0.0; henceforth, it absolutely hindered looseness of the bowels. The negative control aggregate treated with $1.5 \mathrm{ml}$ refined water had the most elevated mean recurrence of fecal (Tables 4 and 5), and thus, there was no hindrance of the runs in this gathering. The concentrate showed noteworthy hostile to diarrheal action against castor oil initiated looseness of the bowels in research facility pale-skinned person rats. There was factually critical lessening $(\mathrm{p}<0.05)$ in the quantity of wet fecal by $78.33 \%$ amid spring season, $78.26 \%$ amid pre-winter season at $600 \mathrm{mg} / \mathrm{kg}$ body weight, and when contrasted with negative control rats. There was no critical distinction $(\mathrm{p}>0.05)$ in percent diminishment of wet fecal for the $200 \mathrm{mg} / \mathrm{kg}$ and $400 \mathrm{mg} / \mathrm{kg}$ rats when contrasted and the negative control gathering. The concentrate, hence, demonstrated measurement subordinate hindrance of the runs as appeared in Tables 4 and 5 amid two distinctive season. Phytochemical screening of the concentrate demonstrated elevated amounts of tannins and flavonoids, and these phytochemicals could be responsible for the antidiarrheal activity observed in this study through inhibition of peristaltic movement. Tannins and tannic acids also denature proteins forming tannates which decrease the intestinal mucosa permeability. The activity of the extract at $600 \mathrm{mg} / \mathrm{kg}$ was comparable to that of loperamide since there was no significant difference ( $p=0.082)$ in the mean number of fecal droppings between these two groups and thus showed a minute variation in their antidiarrheal activity at two different seasons.

\section{DISCUSSION}

In this exploratory work, we have discovered that the P. guajava leaves contain distinctive phytochemical constituents, for example, tannins, steroid glycosides, and flavonoids. Alkaloids and saponins were available in gathered specimens of harvest time and spring having exact moment occasional variety in sum. The low dampness substance of the leaf would frustrate the development of microorganism and capacity life would be high. The aggregate powder ( 8.72 and $8.70 \%$ ) shows that the leaf is nearly rich in mineral components. Corrosive insoluble cinder esteems were discovered 1.4 and $1.6 \%$ and show less measure of silicate materials which exhibit in gathered sample 7.2 and $7.0 \%$ separately.

In intense lethality test, it was accounted for that a measurements of $2000 \mathrm{mg} / \mathrm{kg}$ and was discovered nontoxic, and the creature additionally hints at no poisonous quality amid try.

Mean recurrence of wet faecal droppings was found to diminished with increment in measurement of the ethanolic leaf concentrate of $P$. guajava got amid two unique seasons, with the mean recurrence of poo being lower in the rats that were treated with $600 \mathrm{mg} / \mathrm{kg}$ and higher in the gatherings that were treated with $400 \mathrm{mg} / \mathrm{kg}$ and $200 \mathrm{mg} / \mathrm{kg}$ separately. The mean recurrence of wet fecal droppings for the rats in the loperamide-treated gathering was 0.0 ; consequently, it absolutely restrained looseness of the bowels. The negative control mass treated with $1.5 \mathrm{ml}$ refined water had the most astounding mean recurrence of defecation. Thus, there was no restraint of looseness of the bowels in this gathering. The concentrate showed critical hostile to diarrheal action against castor oil prompted the runs in research center pale-skinned person rats. There was measurably huge decrease $(p<0.05)$ in the quantity of wet dung by $78.33 \%$ amid spring season, $78.26 \%$ amid pre-winter season at 600 $\mathrm{mg} / \mathrm{kg}$ body weight, and when contrasted with negative control rats. There was no noteworthy distinction $(p>0.05)$ in percent decrease of wet excrement for the $200 \mathrm{mg} / \mathrm{kg}$ and $400 \mathrm{mg} / \mathrm{kg}$ rats when contrasted and the negative control gathering.

The action of the concentrate at $600 \mathrm{mg} / \mathrm{kg}$ was practically identical to that of loperamide since there was no critical contrast (p-esteem, 0.082) in the mean number of fecal droppings between these two gatherings and along these lines demonstrated a moment variety in their hostile to diarrheal movement at two unique seasons. Thus, we can infer that the ethanolic concentrate of youthful leaves of P. guajava indicates minute variety in the counter diarrheal constituents.

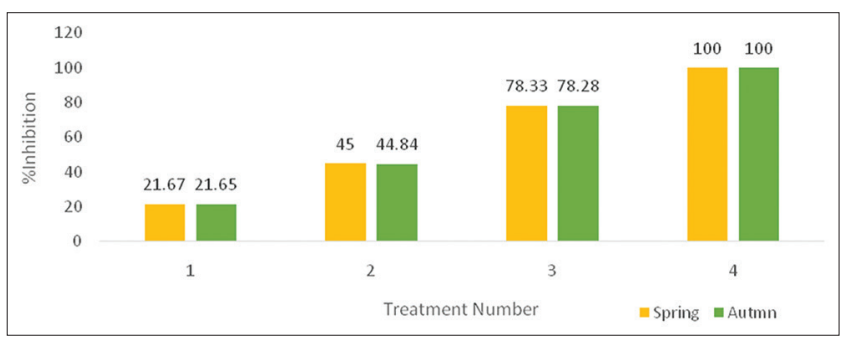

Fig. 1: Comparison of antidiarrheal activity in autumn and spring

Table 4: Effect of the ethanoic extract of P. guajava leaf at dissimilar dose points on castor oil induced diarrhea during spring season

\begin{tabular}{|c|c|c|c|c|c|}
\hline Treatment number & Treatment & Number of wet feces & Percentage inhibition & DF & $\mathbf{p}$ \\
\hline 1 & $200 \mathrm{mg} / \mathrm{kg}$ extract+castor oil & $4.67 \pm 0.0 .95$ & 21.67 & 5 & 0.387 \\
\hline 2 & $400 \mathrm{mg} / \mathrm{kg}$ extract+castor oil & $3.33 \pm 0.0 .49$ & 45.00 & 5 & 0.38 \\
\hline 3 & $600 \mathrm{mg} / \mathrm{kg}$ extract+castor oil & $1.33 \pm 0.61$ & $78.33^{*}$ & 5 & 0.04 \\
\hline 4 & $1 \mathrm{mg} / \mathrm{kg}$ loperamide+castor oil & $0.00 \pm 0.00$ & 100.00 & 5 & 0.01 \\
\hline 5 & $1.5 \mathrm{ml}$ normal saline+castor oil & $6.0 \pm 0.82$ & 0.00 & 5 & - \\
\hline
\end{tabular}

${ }^{*} \mathrm{p}<0.05$, when compared with the negative control, data were expressed as mean \pm SEM, $n=4$, DF: Degree of freedom, SEM: Standard error of the mean

Table 5: Consequence of the ET extract of P. guajava leaf at dissimilar dose levels on castor oil induced diarrhea throughout autumn season

\begin{tabular}{|c|c|c|c|c|c|}
\hline Treatment number & Treatment & Number of wet feces & Percentage inhibition & DF & $\mathbf{p}$ \\
\hline 1 & $200 \mathrm{mg} / \mathrm{kg}$ extract+castor oil & $4.69 \pm 0.0 .95$ & 21.65 & 5 & 0.384 \\
\hline 2 & $400 \mathrm{mg} / \mathrm{kg}$ extract+castor oil & $3.30 \pm 0.0 .49$ & 44.84 & 5 & 0.376 \\
\hline 3 & $600 \mathrm{mg} / \mathrm{kg}$ extract+castor oil & $1.31 \pm 0.61$ & $78.28^{*}$ & 5 & 0.038 \\
\hline 4 & $1 \mathrm{mg} / \mathrm{kg}$ loperamide+castor oil & $0.00 \pm 0.00$ & 100.00 & 5 & 0.01 \\
\hline 5 & $1.5 \mathrm{ml}$ normal saline+castor oil & $6.0 \pm 0.82$ & 0.00 & 5 & - \\
\hline
\end{tabular}

${ }^{*} \mathrm{p}<0.05$, when compared with the negative control, data were expressed as mean \pm SEM, $n=6$, DF: Degree of freedom, SEM: Standard error of the mean, ET: Ethanol 


\section{CONCLUSION}

The leaves remove contains pharmacologically dynamic materials with antidiarrheal properties. The results convey the proposal for variety in phytochemical substance and in addition revision in antidiarrheal movement of ethanoic concentrate of $P$. guajava leaves amid autumn and spring. This could be because of progress in atmosphere or because of change in plant biosynthesis pathway.

\section{ACKNOWLEDGMENT}

The authors are thankful to the Institutional Animal Ethical Committee of Girijananda Chowdhury Institute of Pharmaceutical Science, Guwahati, for providing us necessary animal testing facilities.

\section{REFERENCES}

1. Venu C, Ramanjaneyulu K, Reddy SN, Laxmi V, Alla B. Evaluation of antidiarrhoeal activity of ethanolic extracts of Pithecellobium dulce on castor oil-induced Diarrhoea in albino Wistar rats. Discovery 2016;52:1494-6.

2. Borah U, Dash B, Dash S, Deka J, Kalita L. Preliminary phytochemical screening and in vitro antimicrobial activity of ethanolic extract of whole aerial part of the herb Leucas plukenetii spreng (family-laminaceae). Int J Curr Pharm Res 2017;9:87-90.

3. Gutiérrez RM, Mitchell S, Solis RV. Psidium guajava: A review of its traditional uses, phytochemistry and pharmacology. J Ethnopharmacol 2008;117:1-27.

4. Anand S, Arasakumari M, Prabu P, Amalraj A. Anti-diabetic and aldose reductase inhibitory potential of Psidiumguajava by in vitro analysis. Int J Pharm Pharm Sci 2016;8:271-6.
5. Suyambu R, Shalini R. Antidiarrhoeal activity of aqueous and alcoholic extracts of Hemidesmusindicus root. Int J Pharm Pharm Sci 2015;7:403-6

6. Kurian S, Josekumar VS. Phytochemical screening, antimicrobial activity and brine shrimp lethality bioassay of different extracts of Alysicarpus vaginalis var. nummularifolius (DC.) MIQ. (Family: Fabaceae). Int J Pharm Sci 2017;9:1-6.

7. WHO. Quality Control Methods for Medicinal Plant Materials. Geneva: World Health Organization; 1998.

8. Anonymous. Quality Control Methods for Medicinal Plant Materials (World Health Organization), Geneva, Delhi: AITBS Publishers and Distributors; 2002. p. 51-60.

9. Tiwari P, Kumar B, Kaur M, Kaur, Kaur H. Phytochemical screening and extraction: A review. Int Pharm Sci 2011;1:98-106.

10. Kim DO, Jeong SW, Lee CY. Antioxidant capacity of phenolic phytochemicals from various cultivars of plums. Food Chem 2003;81:321-6.

11. Ejikeme CM, Ezeonu CS, Eboatu AN. Determination of physical and phytochemical constituents of some tropical timbers indigenous to Niger Delta Area of Nigeria. Eur Sci J 2014;18:247-70.

12. Amadi BA, Agomuo EN, Ibegbulem CO. Research Methods in Biochemistry. Owerri, Nigeria: Supreme Publishers; 2004.

13. Katasani D. Phytochemical screening, quantitative estimation of total phenolic, flavanoids and antimicrobial evaluation of Trachyspermumammi. J Atoms Mol 2011;1:1-8.

14. Obadoni BO, Ochuko PO. Phytochemical studies and comparative efficacy of the crude extracts of some hemostatic plants in Edo and Delta States of Nigeria. Glob J Pure Appl Sci 2002;8:203-8.

15. Teke GN, Kuiate JR, Ngouateu OB, Gatsing D. Antidiarrhoeal and antimicrobial activities of Emilia coccinea (Sims) G. Don extracts. J Ethnopharmacol 2007;112:278-83. 